\title{
COMPARISON OF FIVE METHODS FOR ESTIMATING LEAF AREA INDEX OF OPEN- GROWN DECIDUOUS TREES
}

\author{
by Paula J. Peper and E. Gregory McPherson
}

\begin{abstract}
We compared the accuracy of five methods used to estimate leaf area index (LAl) of eight open-grown deciduous trees, including six white mulberries (Morus alba) and two black cherries (Prunus serotina var. rufula). The methods included the use of four instruments (AccuPAR Ceptometer, $\mathrm{Cl}-100$ Plant Canopy Analyzer, image processing with the AgVision System, LI-COR LAl-2000 Plant Canopy Analyzer) and the application of a logarithmic regression equation. The image processing method demonstrated the highest probability of accurately estimating LAI $(P=0.99)$. However, all methods showed bias toward returning $L A I$ estimates that did not increase as actual LAI increased when the mulberry tree data were examined separately from the cherry data. Additional research is necessary to determine whether this bias is real or merely a function of the limited sample size.

Keywords. LAl; leaf area; hemispheric photography; allometry; ceptometer; image processing; plant canopy analyzer
\end{abstract}

Leaf area is a key parameter for studying many physiological processes associated with urban and rural trees. Leaf area index (LAI, leaf area per unit ground area) is highly correlated with photosynthesis, transpiration, evapotranspiration, productivity, and yield rates (Botkin 1986; Pierce and Running 1988; Gholz et al. 1991). Modeling growth rates, atmospheric deposition, biogenic volatile emissions, climate change, and energy exchange associated with open-grown trees in cities requires accurate estimates of LAI (McPherson 1992; Nowak 1994; Winer et al. 1995). However, the majority of research on destructive and nondestructive methods of estimating leaf area has been conducted on forest canopies, orchards, and agricultural row crops (Norman and Welles 1983; Lang and Yuequin 1986; Norman and Campbell 1989; Lang and McMurtrie 1992; Martens et al. 1993; Nel and Wessman 1993).

Indirect methods for determining LAI include the use of allometric equations (Whittaker and Woodwell 1968; Marshall and Waring 1986; Martens et al. 1993; Nowak 1996). Nowak de- veloped allometric equations to predict leaf area and leaf biomass for open-grown deciduous urban trees based on stem diameter and crown parameters. Other indirect methods, including hemispheric photographs (Bonhomme and Chartier 1972; Neumann et al. 1989; Martens et al. 1993) and gap fraction analysis, have been applied almost exclusively to forest and agricultural canopies (Norman and Welles 1983; Lang and Yuequin 1986; Norman and Campbell 1989; Martens et al. 1993; Nel and Wessman 1993). The exception to this is Lang and McMurtrie's use of the DEMON instrument to estimate leaf areas of single Eucalyptus grandis trees (Lang and McMurtrie 1992). Film and video image processing is the method most commonly tested on opengrown and containerized deciduous trees (Wagar and Heisler 1986; Gardner and Sydnor 1987; Wilkinson 1991; Lindsey and Bassuk 1992).

The objective of this pilot study was to test a variety of instruments and data analysis methods, initiating a first step toward finding a single accurate and efficient technique for nondestructively determining leaf area over the wide variety of tree species present in the urban landscape. Nowhere is it more difficult to obtain accurate LAl measurements than in urban settings, where few residents are willing to proffer their yard and street trees to destructive sampling by urban forest researchers. Pedestrian and vehicular traffic limit the placement and amount of mensuration equipment that can be set up and utilized safely. Also, buildings, signs, and other objects often shade parts of tree crowns at various times of the day. Therefore, the primary objective of this study was to identify the most accurate and efficient method(s) that can be utilized in a variety of urban settings throughout the course of a day. 


\section{Methods}

We tested four equipment systems and a logarithmic regression formula on six to eight open-grown trees (sample size depended upon method employed). The systems were hemispheric sensors (LI-COR LAl-2000 Plant Canopy Analyzer, CID Cl100 Computer Canopy Analyzer), linear array of PAR sensors (Decagon Devices AccuPAR Ceptometer), and a photographic system (Decagon Devices AgVision System used in conjunction with Lindsey and Bassuk's [1992] photo image analysis method). Photosynthetically active radiation (PAR) data from the LAl-2000 were processed using three methods. Data from the AccuPAR were analyzed as they came from the instrument and also by removing measurements recording no differences between above- and below-crown PAR. Image files from the $\mathrm{Cl}-100$ were processed using original software that came with the instrument and an updated software program currently being researched and developed. Lastly, we compared results from the application of Nowak's logarithmic regression equation for predicting leaf area to the actual leaf area on six trees sampled in the study.

Study site. Measurements and complete destructive sampling of eight open-grown trees were begun in July 1995 and completed in early October 1995 at the Solano Urban Forest Research Area (SUFRA) at Solano Community College near Fairfield in northern California. The climate at the facility is under a maritime influence and temperatures typically range from $24^{\circ} \mathrm{C}$ to $35^{\circ} \mathrm{C}\left(75^{\circ} \mathrm{F}\right.$ to $\left.95^{\circ} \mathrm{F}\right)$ during summer months. Typically, summer days are sunny and cloudless. Winds are ever present and may gust to $1.34 \mathrm{~m} \cdot \mathrm{s}^{-1}(30 \mathrm{mph}$ ) by late afternoon. A residential community borders two sides of the site.

The study trees included six white mulberries (Morus alba) planted at the site from $22-\mathrm{L}$ (5-gal) containers in 1985. Their trunk diameters at breast height ( $\mathrm{dbh}$ ) ranged from 12.9 to 19.4 $\mathrm{cm}$ (5 to $7.6 \mathrm{in}$.). Total tree height and crown width ranged from 4.4 to $8.1 \mathrm{~m}$ (14.4 to $16.6 \mathrm{ft}$ ) and 6.1 to $8.25 \mathrm{~m}$ (20 to $27 \mathrm{ft}$ ), respectively. Tree shape was ellipsoidal. However, the prevailing southwest winds in the area had produced crowns wider on the northeast sides of the trees than on the southwest sides. The trees tended to have long, leggy upper branches with many gaps.

Two black cherries (Prunus serotina var. rufula) included in the study were planted in 1986. Their crowns exhibited no shaping effects from the wind and were vertically ellipsoidal with trunk diameters of 20.4 and $20.9 \mathrm{~cm} \mathrm{(8.03}$ and 8.22 in.) at breast height. Tree heights were 7.5 and $7.7 \mathrm{~m} \mathrm{(24.6}$ and $25.26 \mathrm{ft}$ ), and crown widths were both $4.6 \mathrm{~m}(15 \mathrm{ft})$. Both species received regular pruning in the first several years of planting to remove low-growing branches and epicormics. The cherries were further pruned to increase crown density and improve form. The six mulberries and two cherries were randomly selected from extremely limited populations of twelve and five trees, respectively. However, for the purpose of this pilot study, the assumption is the selection of these trees is as good as if chosen at random from larger populations.

General data collection. Before any of the techniques under evaluation were applied, the following measurements were taken for each tree: 1) dbh; 2) tree height; 3) bole height; 4) crown height; 5) crown diameter in two perpendicular directions; 6) crown shape-paraboloid or vertical ellipsoid; 7) crown vigor based on a) measurements of the last three years' twig elongation, twelve branches per tree, b) percentage of crown dieback, and c) foliage discoloration, as per methods described in the Forest Health Monitoring Field Methods Guide (Burkman et al. 1993). Lastly, eight pairs of $x, y$ coordinates that defined the outermost limits of the crown were measured for later use in adjusting the LAI-2000 path lengths.

Random distances along $\mathrm{x}, \mathrm{y}, \mathrm{z}$ coordinates from the tree base were selected to determine leaf sampling locations within each tree crown. Using a break-apart frame made from PVC pipe $\left(0.016 \mathrm{~m}^{3}\left[0.565 \mathrm{ft}^{3}\right]\right), 20$ samples of foliage were collected in two stages. After each set of 10 quadrat samples were harvested, measurements of the crown were repeated for all methods. The use of pruning ladders enabled collection without disturbing the tree crown. Each sample was weighed fresh, and all leaves were measured for leaf area 
using leaf area image analysis (Decagon Devices, Inc., Pullman, Washington). Samples were then dried $\left(65^{\circ} \mathrm{C}\left[149^{\circ} \mathrm{F}\right]\right.$ for $\left.24 \mathrm{~h}\right)$ and weighed. Subsample fresh:dry weight and dry weight:leaf area ratios were calculated for each of the 20 samples. Mean values and standard deviations were estimated for each tree's sample.

After quadrat sampling and instrument measurements were completed, all remaining leaves were removed from the crown for a $100 \%$ destructive sample. These leaves were dried and weighed to obtain total dry weight of foliage for each tree. Mean leaf area:dry weight ratios were multiplied by the weight of the $100 \%$ destructive sample to calculate total leaf area per tree (control). Leaf area index for the control was calculated by dividing total leaf area by crown projection. The experiment was established as a randomized block design, with three repeated measurements. Each block consisted of a single tree; LAI measurements were repeated three times per tree, once with the tree in full crown, then after removing leaves from ten randomly selected $0.016 \mathrm{~m}^{3}\left(0.565 \mathrm{ft}^{3}\right)$ quadrats, and again after removing leaves from an additional 10 quadrats. Analyses of variance were conducted on the differences between actual and estimated LAI for each method to estimate standard errors. There were two variance components, one due to random effect block (tree) and the other due to variability within the block. Paired t-tests were run on resulting sample means:

$$
\mathrm{t}=|\overline{\mathrm{z}}| \div \mathrm{SE}(\overline{\mathrm{z}})
$$

where $|\bar{z}|$ is the absolute value of the sample mean (Mori 1996). The alpha level was set to 0.05 and the critical point, $t_{d \text {, }}$ was read from tables with the t-distribution at 5, 6, and 7 degrees of freedom, depending on the number of sample trees included in the analysis.

Instrument sampling and analytical methods. For repeated measurements to be taken with the LAl-2000, $\mathrm{Cl}-100$, and AccuPAR from the exact same locations beneath the tree crown, four stakes were driven into the earth, one in each cardinal direction, $20 \mathrm{~cm}(7.87 \mathrm{in}$.) from the base of the bole, $15 \mathrm{~cm}$ (5.91 in.) above ground level, and approximately 0.9 to $1.3 \mathrm{~m}$ (2.95 to $4.27 \mathrm{ft}$ ) below the bottom of each crown. Each instrument's probe was then leveled while resting on top of the stake and a single measurement taken in each cardinal direction for a full tree crown, then again after the crown was reduced by ten $0.016 \mathrm{~m}^{3}\left(0.565 \mathrm{ft}^{3}\right)$ samples of leaves, and finally after a total of twenty $0.016 \mathrm{~m}^{3}\left(0.565 \mathrm{ft}^{3}\right)$ samples were removed. Instrument photos and measurements for the image analysis method (Lindsey and Bassuk 1992) were taken in sequence, starting with photographs of the tree crown in two perpendicular directions, then following in order with the LAI-2000, AccuPAR, and $\mathrm{Cl}-100$. Photographs and measurements for each tree were completed in approximately $45 \mathrm{~min}$.

Because one of the parameters of this study was to duplicate the conditions under which LAl measurements will be taken in urban settings, all instrument readings were taken under clear sky conditions, at easily accessible locations at the base of each tree bole, at a range of times between 0800 and $1700 \mathrm{~h}$ (PST).

AccuPAR PAR Ceptometer. This instrument is a battery-operated linear PAR ceptometer used to measure photosynthetically active radiation in the 400-to-700-nm waveband. It consists of an integral, programmable data logger and 80 independent sensors located at $1 \mathrm{~cm}^{2}\left(0.39 \mathrm{in.}^{2}\right)$ intervals along the length of the attached probe (Decagon Devices, Inc., Pullman, Washington). Most analytical methods for determining LAI assume that canopy elements are randomly dispersed in space. In reality, canopies exhibit some degree of clumping, and the assumption of randomness results in a large source of error (Norman and Campbell 1989). The sensors along the AccuPAR probe may be partitioned into groups to mimic the clumping effects of a canopy. Because of the near-constant presence of wind at SUFRA, partitioning to mimic clumping within crowns was not feasible; the clumps and distribution of foliage changed from moment to moment. As a result, the probe was divided into five groupings containing 16 sensors each. The instrument then collected data on each group of sensors, and the software program averaged the readings from the sensors to produce the LAl. Latitude, longitude, international date, and standard local time for the site also 
were programmed into the data logger for automatic calculation of zenith angle. The programmed leaf distribution parameter was 1.0. Fractional beam data (the amount of diffuse and direct beam radiation reaching the canopy) were measured for each set of above- and below-crown measurements. Although the instrument prompts the operator to measure fractional beam, it does not automatically record the information for later use, but simply uses it to calculate the LAI with an ellipsoidal inversion formula. A single sensor was used to record above- and below crown measurements. Above-crown data were taken by walking into an open field adjacent to the study trees. For belowcrown measurements, the instrument was placed on the top of the stakes. Gap fraction and LAI were computed by the instrument for each direction using Campbell and Norman's method (1988):

$$
L=\frac{\left[\left(1-\frac{1}{2 K}\right) f_{b}-1\right] \ln \mathrm{T}}{A\left(1-0.47 f_{b}\right)}
$$

where $A=0.283+0.785 a-0.159 a^{2}$, and $a$ is the leaf absorptivity in the PAR band (AccuPAR assumes 0.9 in LAl sampling routines). $T$ is the transmission coefficient, and $K$ is the extinction coefficient for the crown. Average LAl also was calculated for the four directions. Gap measurements producing gap fractions $\geq 1$ were noted and recorded during field work.

Cl-100 Plant Canopy Analyzer. The $\mathrm{Cl}-100$ (CID, Inc., Vancouver, Washington) uses a digital camera with a fisheye (150-degree) lens positioned

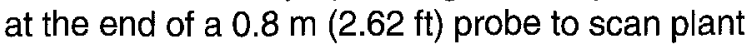
canopies. Up to 32 measurements can be taken in the field before downloading high-resolution images to a IBM PC-compatible computer. Using a laptop computer while taking measurements allows the researcher to see the crown or canopy being measured and adjust the image if necessary. The instrument can be used under sunny, cloudy, or partly cloudy sky conditions. During image analysis, the $\mathrm{Cl}-100$ software first divides the image into a user-defined number of zenith and azimuthal divisions then analyzes the fraction of sky (solar beam transmission coefficient) visible in each sector by tallying the light (monochrome

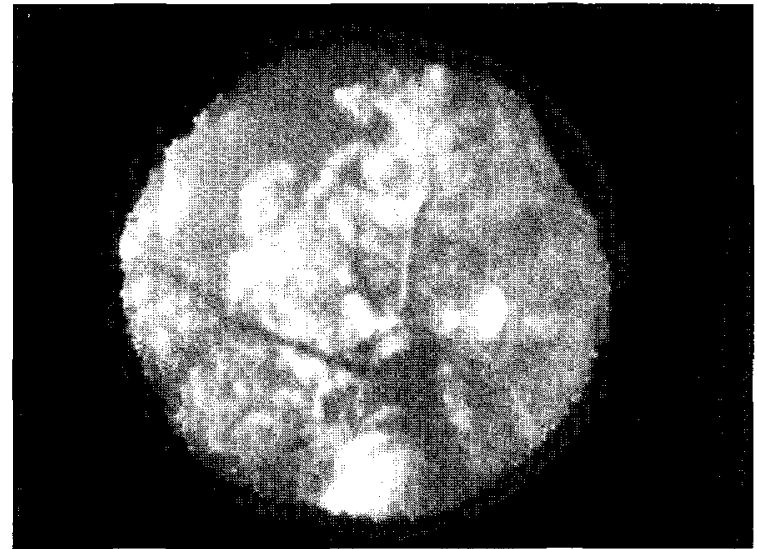

Figure 1. Original photographic image of mulberry captured by the $\mathrm{Cl}-100$.

monitor) or blue-colored (color monitor) pixels in that sector. After all sectors have been analyzed, average solar beam transmission coefficients for each zenith division are computed. Estimates of leaf area index, leaf distribution, mean foliage inclination, transmission coefficients for diffuse and radiation penetration, and extinction coefficient are produced. The software (IBM-PC compatible only) also allows for later downloading of the images and further image adjustments, including the masking of areas on the screen, threshold adjustment, and the selection of individual zenith angle for use in LAl calculations.

An image-adjustment option is available to verify that the center of the image on the laptop computer screen is also the physical center of the fisheye lens. No adjustments were necessary during this study. Five zenith and four azimuthal divisions were selected, and threshold was placed on automatic. Four images for each crown reduction level (full crown, $-10,-20$ quadrat samples) were captured for each tree by placing the fisheye lens at the end of the probe on top of the stakes at the base of the tree bole (Figure 1). Whole-tree LAI was calculated from the average of the four software-processed images. The software uses an ellipsoidal inversion modification of the Beer-Lambert method for LAI computations:

$$
L=-\sum_{\varphi_{i}=\varphi_{1}}^{\varphi_{n}} \frac{\ln T_{\varphi_{i}}}{K_{\varphi_{i}}}
$$


where $\varphi_{i}$ is the $i$ th solar elevation angle division ( $n$ is the number of divisions selected), $T$ is the transmission coefficient, and $K$ is the extinction coefficient of the canopy:

$$
K_{\varphi}=\frac{\sqrt{x^{2}+\tan ^{2} \varphi_{i}}}{A}
$$

where $A=x+1.774(x+1.182)^{-0.733}$, and $x$ represents leaf angle distribution (Norman and Campbell 1989).

Image analysis method with AgVision Pseudo-Color System. This method converts a two-dimensional photograph into an estimate of leaf area index using a unitless quantification of tree crown density called silhouette area (SA) as follows:

$$
L A I=\frac{S A \times P F A}{C P A}
$$

where PFA is the actual photograph's scaled frame area and CPA is the crown projection area of the tree. SA is the percentage of the total viewing field on the monitor that is composed of tree crown (Lindsey and Bassuk 1992):

$$
S A=\frac{\text { Crown area }}{\text { Frame area }}
$$

The term "SA" evolved from an understanding that, in a three-dimensional crown, certain portions of leaf area remain "unseen" due to leaf overlap, resulting in an underestimation of actual leaf surface area, while inclusion of the stem results in an overestimation. It has been found that when an image processing system

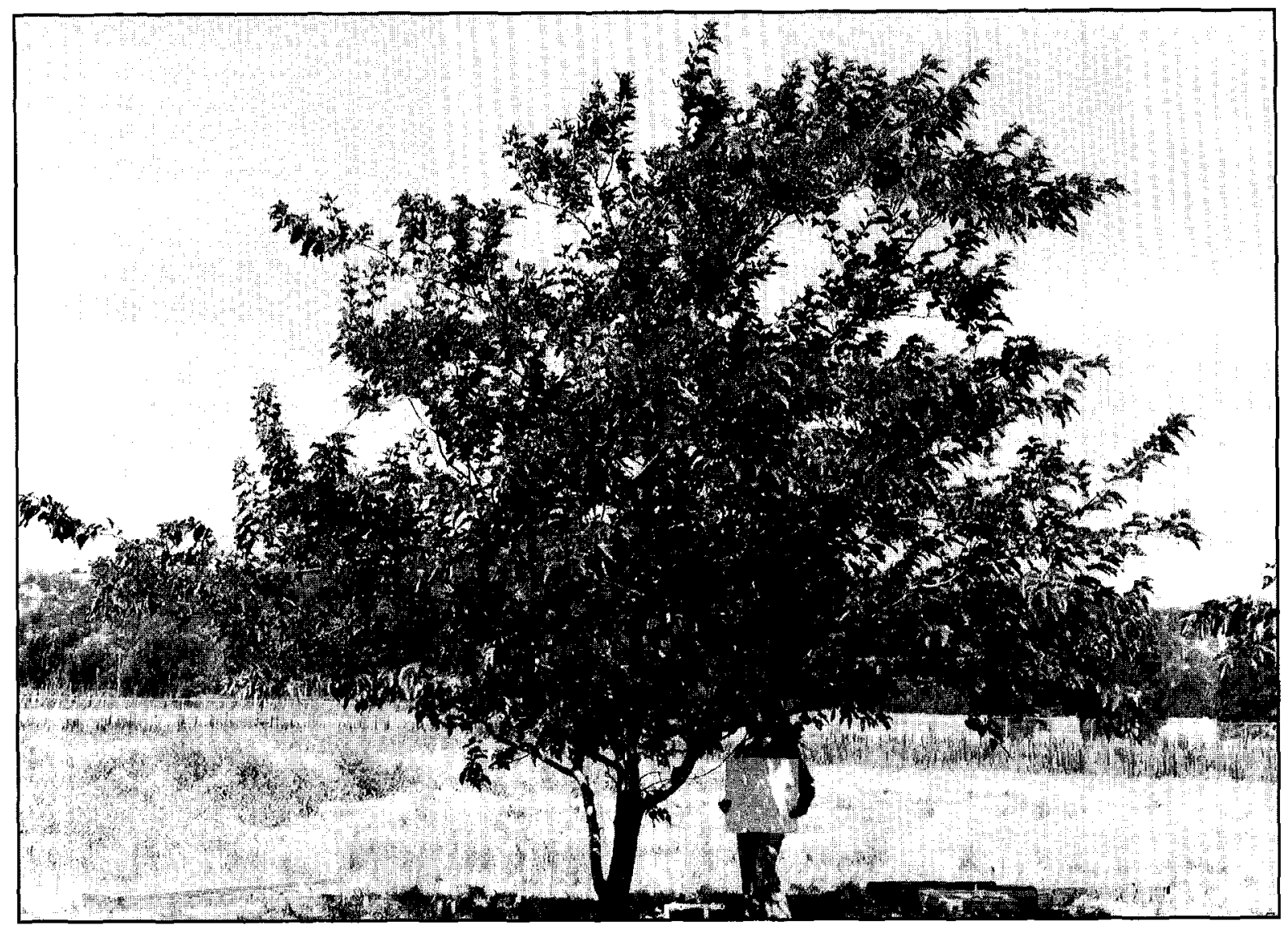

Figure 2. Profile view of mulberry (same tree as in Figure 1) before the original 35-mm photograph was video scanned into the AgVision System. 
is set in area mode, the resulting SA is highly correlated with more conventional methods of indirectly estimating needle surface area (Lindsey and Bassuk 1992).

For this study, two perpendicular photographs (90-degree angles) were taken of each tree in full crown, then again after ten and twenty $0.016 \mathrm{~m}^{3}\left(0.565 \mathrm{ft}^{3}\right)$ quadrat leaf samples were removed, for a total of six photographs per tree (Figure 2). A handheld 35-mm Nikon FE with a $55-\mathrm{mm} 2.8$ lens was used. Shutter speed was adjusted to maintain an f-stop of no less than 8.0 for good depth of field. Kodak Tri-X Pan, 400 ASA black-and-white negative film was selected for its speed and fine grain. A $0.25 \mathrm{~m}^{2}\left(2.69 \mathrm{ft}^{2}\right)$ poster board was held next to the bole of each tree as a scale. The three pairs of photographs were taken at the same bearings, but not necessarily at the same distances. Film was processed using manufacturer's recommended development and printing techniques, chemicals, and paper. Each negative was enlarged so that the crown and bole of the tree filled the largest area possible of a $19.0 \times 24.5 \mathrm{~cm}(7.5 \times$ 9.6 in.) frame. Kodak Polycontrast III resincoated paper and a 2.5 polycontrast filter were used. Prints were processed using Kodak Dektol Developer.

The next step was to use the AgVision Pseudocolor System (Decagon Devices, Inc., Pullman, Washington) to analyze the images. This system consists of a 386 IBM-AT compatible $40 \mathrm{MHz}$ computer, a CCD video camera, VGA computer monitor, 14-in. color video monitor, camera stand assembly, and software. Photographs of the tree crowns were placed individually in an adjustable print easel on the camera/light stand. The photograph was then viewed via the video camera on the color video monitor. The system processed the image into numerical information with a digitizer and microcomputer and displayed it on the computer monitor for processing.

To calculate LAI, the system was calibrated to the $0.25 \mathrm{~m}^{2}\left(2.69 \mathrm{ft}^{2}\right)$ poster-board scale in each photograph. Using paint and erase tools, all nontree crown components of the image were removed. Once the tree crown was isolated and highlighted, the software calculated total tree crown area (CA). Subsequently, the entire frame (the video screen area) was highlighted and frame area (FA) calculated. The unitless surface area value, called silhouette area (SA), was then obtained by dividing the crown area by the frame area.

Conversion of this SA number into estimated leaf area index required five additional steps including 1) scaling from the negative, 2) obtaining frame dimensions from print, 3) scaling from the negative to the print, 4) calculating total leaf area, and 5) converting to leaf area index (Lindsey and Bassuk 1992). First, the scale of the negative taken with a $55-\mathrm{mm}$ lens was calculated as the representative fraction:

$\frac{\text { Camera focal length }(55 \mathrm{~mm})}{\text { Distance from camera to tree }}$

Numerator and denominator were each divided by $5.5 \mathrm{~cm}$ to yield the negative scale $(1 \mathrm{~cm}$ on the negative $=x \mathrm{~cm}$ in reality).

Second, the arms on the print easel holding the photograph on the light stand were adjusted so that the square frame captured all of the tree crown. The photo's frame dimensions were recorded. Third, an object of known size (poster board) on the negative was compared to the poster board on the print to determine an enlargement ratio. Fourth, the frame dimensions were divided by this enlargement ratio and then multiplied by the negative scale in Step 1 to obtain the final adjusted photo frame area (PFA). Estimated leaf surface area for the tree was calculated by multiplying PFA by the mean percentage of SA. Dividing this product by the crown projection area of the sample tree produced the leaf area index. The average estimated total leaf area obtained from the two photos taken of each tree was used to calculate leaf area index for the eight trees in our sample.

\section{LI-COR LAl-2000 Plant Canopy Analyzer.} The LAI-2000 (LI-COR Inc., Lincoln, Nebraska) sensor head projects a nearly hemispheric view onto five concentric silicon ring detectors. A dedicated data logger is connected to the optical sensor and records ring detector readings of aboveand below-canopy light conditions at five zenith angles. Built-in software and additional utilities 
software enable extended analysis of the data files.

The ideal conditions for taking readings with the LAI-2000 call for uniformly overcast skies. An alternative is to take measurements at sunset or sunrise to preclude underestimation of LAI (Welles and Norman 1991). Because our measurements were taken during daylight on sunny days, shading of the lens and a 90-degree view cap were used to restrict direct sunlight from striking the optical sensor. Four pairs of above- and below-crown readings were taken, one pair in each cardinal direction. As with the AccuPAR, above-crown data were taken by walking into an open field adjacent to the study trees. The below-crown readings (again with 90-degree view cap) were taken 90 degrees apart. The mean of these values was stored in the instrument. Records were maintained, noting measurements for which sunlight directly struck the probe (resulting in transmittance $>1$ ) so that these could be verified when using software to remove records with $>1$ transmittance. Leaf area index was computed by instrument software using the following formula:

$$
L A I=2 \sum_{i=1}^{5} K_{i} W_{i}
$$

where $K_{i}$ is the contact frequency, equivalent to the average number of contacts per unit length of travel that a probe would make passing through the crown at zenith angle $\theta$, and the values of $W$ are computed by breaking the interval 0 to 90 degrees into five uneven intervals based on the center angles assigned to each detector ring. When normalized to sum to 1.0 , the values of $W$ are $0.034,0.104,0.160,0.218$, and 0.494 , respectively, for angles of $7,23,38,53$, and 68 degrees.

Subsequently, the instrument's default values for the five distance vectors were adjusted for each tree's crown. Leaf area index was then computed using Lang's method (1987):

$$
\mathrm{LAI}=2(\mathrm{~S}+\mathrm{I})
$$

where $S$ and I are the slope and intercept of the mean contact number (the average number of contacts per unit length of travel that a probe would make passing through the crown at zenith angle $\theta$ ) plotted against zenith angle $\theta$ (in radians).

Lastly, leaf area index was recomputed using the ellipsoidal inversion model discussed previously (Campbell 1986; Norman and Campbell 1989). Because the LAl-2000 measures transmittance at five solar zenith angles simultaneously, this model is applicable. All methods used to compute LAl are integrated into the LAI2000 software program and easily applied to the PAR data collected in the field.

Logarithmic regression equation for leaf area. Nowak (1996) develped a logarithimic regression equation to predict leaf area of opengrown deciduous urban trees based on crown parameters. The equation is of the form:

$$
\begin{aligned}
\ln Y= & -4.3309+0.2942 H+0.7312 D+5.7217 S \\
& +-0.0148 C+\text { error }
\end{aligned}
$$

where $Y$ is leaf area $\left(\mathrm{m}^{2}\right), H$ is crown height $(\mathrm{m})$, $D$ is average crown diameter $(m), S$ is percentage of light intensity intercepted by foliated tree crowns (average shading factors), and $C$ is $\pi D(H+D) / 2$, based on the outer surface area of the tree crown. The back-transformed estimated response, $\hat{Y}$, was multiplied by $e^{\mathrm{MSE} / 2}$ to correct for the bias due to the logarithmic transformation (Baskerville 1972). The correction factor was added to the untransformed estimates (Nowak 1996). The regression coefficients were derived by Nowak from a study of 54 healthy trees representing five species for application to all opengrown species. A 0.78 shading factor for Morus alba (McPherson et al. unpublished data) was used. Because we were unable to find a shading factor for black cherries in the literature, only the mulberry data are compared in this study. The estimated leaf areas were divided by tree crown projections to produce leaf area index estimates.

\section{Results and Discussion}

For analysis purposes, it was assumed that the change in tree foliage area, due to the two harvests of 10 quadrat samples each, was negligible. Actual LAI measurements after total destructive 
Table 1. The range of measurements, from highest to lowest, taken for each tree for actual leaf area index and estimates. Three measurements were taken for each tree at three levels of crown foliation, but decreases in actual leaf area with removal of each 10-quadrat sample of leaves were not reflected by the estimation methods; estimates made at reduced crown levels were often higher than full-crown estimates. Only the actual measurements decreased with leaf removal.

\begin{tabular}{lllllll} 
Tree & Actual & AccuPAR & Cl-100 & Image & LAl-2000 & Logarithm \\
\hline Mulberry 01 & $3.15-3.12$ & $2.16-1.48$ & $2.92-2.65$ & $3.06-2.72$ & $4.25-2.86$ & 3.32 \\
Mulberry 02 & $2.26-2.25$ & $1.12-0.37$ & $3.38-3.31$ & $2.65-2.14$ & $4.16-1.65$ & 3.73 \\
Mulberry 03 & $3.89-3.86$ & $1.30-0.92$ & $3.65-2.70$ & $2.80-2.29$ & $3.51-2.05$ & 3.13 \\
Mulberry 04 & $3.58-3.57$ & $1.61-0.42$ & $4.07-2.66$ & $3.55-3.21$ & $2.98-2.52$ & 4.08 \\
Mulberry 05 & $3.24-3.22$ & $1.59-1.35$ & $3.91-3.43$ & $2.72-2.53$ & $2.84-2.46$ & 3.18 \\
Mulberry 06 & $2.35-2.34$ & $<0.00$ & n/a & $3.35-3.00$ & $3.23-0.83$ & 2.86 \\
Cherry 01 & $6.29-6.26$ & $1.92-0.99$ & $3.30-2.37$ & $6.05-5.89$ & $7.57-4.17$ & $\mathrm{n} / \mathrm{a}$ \\
Cherry 02 & $4.89-4.86$ & $2.48-0.49$ & $4.12-3.29$ & $7.24-6.35$ & $4.61-2.73$ & $\mathrm{n} / \mathrm{a}$ \\
\hline
\end{tabular}

harvests confirmed this, revealing a total maximum reduction in LAI of 0.03 for any one tree after harvests were completed (Table 1). Although Table 1 presents the data ranges from highest to lowest actual and estimated LAls, all instrument and photographic methods routinely returned estimates after crown reduction that were higher than their full-crown estimates. None of the estimation methods were sensitive enough to capture these small levels of crown reduction. Replication of measurements after crown reductions were used for estimating the within tree variability.

The samples for the AccuPAR, image processing method, and LAl-2000 included eight blocks (one block = one tree) and three repeated measurements $\left(\alpha=0.05, t_{7}=2.365\right)$. The $\mathrm{Cl}-100$ sample included seven trees and three repeated measurements $\left(\alpha=0.05, t_{6}=2.447\right)$, and the regression equation method included six trees with no repeated measurements $\left(\alpha=0.05, \mathrm{t}_{5}=\right.$ 2.57). Tests initially run on data as they came from each instrument (Table 2) without any prior processing showed no significant difference $(\propto=$ 0.05 ) between the actual mean leaf area index of 3.69 and the image processing estimated mean $\mathrm{LAl}$ of $3.70(\mathrm{t}=0.017)$. The tail probability of statistic $t$ was large $(P=0.99)$. The t-test results reveal potential for using the image processing method to estimate leaf area indices. Plotting these estimates against the actual leaf area (Figure $3 c$ ) initially seems to support this finding. The method appears to be fairly precise, as indicated by the small amount of spread between estimated
LAI measurements for each tree. For example, the three measurements of mulberry 02 , representing the tree in full crown, then after 10 and 20 quadrat sample crown reductions, show an LAl spread of 2.14 to 2.65 , compared to an actual spread of 2.25 to 2.26 (Table 1 and Figure 3c).

The sample for the logarithmic regression equation method included the six mulberry trees. Paired t-tests run on the actual and regression equation data resulted in no significant difference. The $P$-value was high $(P=0.36$ for $\propto=0.05)$, and estimated mean LAl was 3.38 compared to actual LAI 3.08.

There were significant differences $(P<0.01)$ between actual and estimated leaf area indices for the AccuPAR, $\mathrm{Cl}-100$, and $\mathrm{LAl} 2000(\mathrm{t}=6.280$, 6.599 , and 5.722 , respectively), revealing that the instruments, with resultant data processed as stated herein, did not adequately estimate leaf area. As a result, we reprocessed data from the instruments using the additional methods described below.

AccuPAR. Measurements producing gap fractions $\geq 1$, the result of early morning and late afternoon low solar zenith angles or missing portions of the tree crown, were removed from the data and recomputed for LAI. The t-tests continued to reveal a significant difference between actual and AccuPAR leaf area indices (3.69 and 1.11 , respectively; $\mathrm{t}=6.177, P<0.01$ ).

Cl-100. Initially, LAI was severely underestimated by the instrument. The original program software did not allow viewing of the actual fisheye 

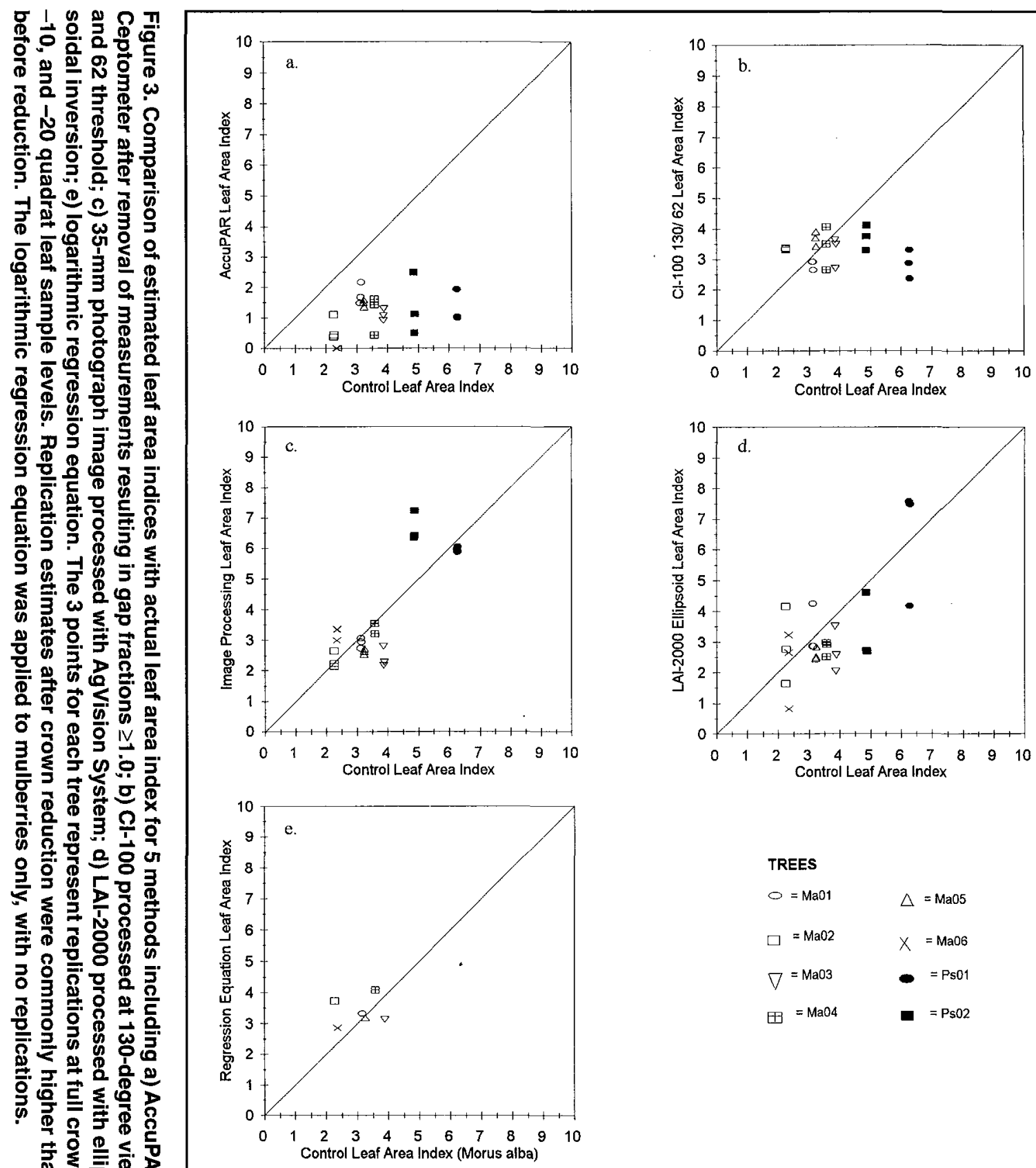

TREES

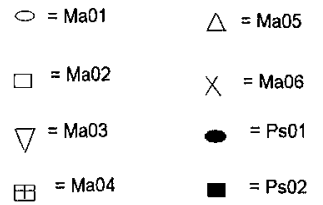

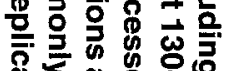

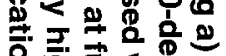

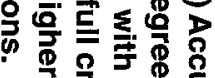

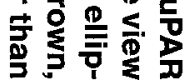
Control Leaf Area Index (Morus alba) 
Table 2. Paired t-test results for original leaf area index data (no processing) and data processed using the methods listed. Analyses of variance were conducted prior to t-tests for all methods to estimate the standard errors, with the exception of logarithmic regression. Methods produced LAl estimates significantly different from actual LAI at 0.05 -level if $t>t$-critical.

\begin{tabular}{|c|c|c|c|c|c|c|c|c|c|}
\hline Method & Processing & $\begin{array}{l}\text { Mean } \\
\text { Estim. } \\
\text { LAI }\end{array}$ & $\begin{array}{l}\text { Sample } \\
\text { Mean } \\
\text { Difference } \\
(\bar{z})\end{array}$ & 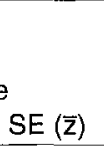 & $\mathrm{n}$ & df & $t$ & $P$-value & $\begin{array}{l}t \text { critical } \\
\alpha=0.05 \\
(2 \text {-tail) }\end{array}$ \\
\hline Actual & $100 \%$ destructive harvest & $\begin{array}{l}3.694 \\
3.887 \\
3.076\end{array}$ & $\begin{array}{l}n / a \\
n / a \\
n / a\end{array}$ & $\begin{array}{l}0.261^{*} \\
0.273 \\
0.266\end{array}$ & $\begin{array}{l}24 \\
21 \\
6\end{array}$ & $\begin{array}{l}7 \\
6 \\
5\end{array}$ & $\begin{array}{l}- \\
-\end{array}$ & $\begin{array}{l}- \\
- \\
-\end{array}$ & $\begin{array}{l}- \\
-\end{array}$ \\
\hline AccuPAR & $\begin{array}{l}\text { None } \\
\geq 1 \text { transmissions removed }\end{array}$ & $\begin{array}{l}0.947 \\
1.107\end{array}$ & $\begin{array}{l}2.747 \\
2.587\end{array}$ & $\begin{array}{l}0.403 \\
0.419\end{array}$ & $\begin{array}{l}24 \\
24\end{array}$ & $\begin{array}{l}7 \\
7\end{array}$ & $\begin{array}{l}6.28 \\
6.177\end{array}$ & $\begin{array}{l}<0.01 \\
<0.01\end{array}$ & $\begin{array}{l}2.365^{\dagger} \\
2.36^{\dagger}\end{array}$ \\
\hline $\mathrm{Cl}-100$ & $\begin{array}{l}\text { None } \\
130^{\circ} \mathrm{w} / 62 \text { threshold } \\
130^{\circ} \mathrm{w} / \text { mixed thresholds } \\
150^{\circ} \mathrm{w} / 62 \text { threshold } \\
150^{\circ} \mathrm{w} / \mathrm{mixed} \text { thresholds }\end{array}$ & $\begin{array}{l}0.354 \\
3.304 \\
2.871 \\
3.102 \\
2.949\end{array}$ & $\begin{array}{l}3.533 \\
0.583 \\
1.016 \\
0.785 \\
0.938\end{array}$ & $\begin{array}{l}0.535 \\
0.547 \\
0.486 \\
0.541 \\
0.467\end{array}$ & $\begin{array}{l}21 \\
21 \\
21 \\
21 \\
21\end{array}$ & $\begin{array}{l}6 \\
6 \\
6 \\
6 \\
6\end{array}$ & $\begin{array}{l}6.599 \\
1.065 \\
2.089 \\
1.45 \\
2.009\end{array}$ & $\begin{array}{l}<0.01 \\
0.33 \\
0.08 \\
0.2 \\
0.09\end{array}$ & $\begin{array}{l}2.447^{\dagger} \\
2.447 \\
2.447 \\
2.447 \\
2.447\end{array}$ \\
\hline $\begin{array}{l}\text { Image } \\
\text { processing }\end{array}$ & None & 3.7 & -0.006 & 0.345 & 24 & 7 & 0.017 & 0.99 & 2.365 \\
\hline LAI-2000 & $\begin{array}{l}\text { None } \\
\text { Lang method } \\
\text { Ellipsoidal inversion }\end{array}$ & $\begin{array}{l}1.107 \\
3.099 \\
3.287\end{array}$ & $\begin{array}{l}2.588 \\
0.467 \\
0.407\end{array}$ & $\begin{array}{l}0.452 \\
0.235 \\
0.26\end{array}$ & $\begin{array}{l}24 \\
24 \\
24\end{array}$ & $\begin{array}{l}7 \\
7 \\
7\end{array}$ & $\begin{array}{l}5.722 \\
1.988 \\
1.565\end{array}$ & $\begin{array}{l}<0.01 \\
0.09 \\
0.16\end{array}$ & $\begin{array}{l}2.365^{\dagger} \\
2.365 \\
2.365\end{array}$ \\
\hline $\begin{array}{l}\text { Logarithmic } \\
\text { regression }\end{array}$ & None & 3.383 & -0.307 & 0.181 & 6 & 5 & -1.017 & 0.36 & 2.015 \\
\hline
\end{tabular}

*Standard error for mean actual LAI, not $\bar{z}$.

tIndicates sample mean significants different from zero.

image, only the processed image. Upon examining the latter, it appeared that the automatic threshold feature had stopped working correctly, varying radically when measurements were repeatedly taken at 30-s intervals from the same location. The original image files were imported into a shareware program that allowed nonprocessed camera images to be viewed. The processed image was then overlaid on the photo image and its threshold adjusted to match the photo image from the camera. Original thresholds had ranged from 90 to 150 on a scale of 0 to 255 .

The instrument is a new product of CID, Inc.- - the one we used being the 15th the company produced up until May 1995. Upon contacting their engineers to discuss the thresholding problem, we were informed that they were developing new software (Yan 1996) to adjust for the thresholding problem. A research and development version of this new software was obtained; the original images were loaded and rerun at a zenith angle of 150 degrees and mixed threshold levels ranging from 58 to 63 on a new threshold scale of 0 to 100 (see Cl-100 150/mix in Table 2). In this instance, thresholds were again adjusted by overlaying the original photo image with the processed image. Next, a mean threshold level of 62 was calculated from the software-calculated threshold levels of the 28 images and they were rerun using this mean threshold. Lastly, we reprocessed the images using mixed and mean thresholds and a zenith angle of 130 degrees, removing the outermost ring because little, if any, foliar matter was present at that zenith angle. Processing the images at a mean threshold level, whether at 130 or 150 degrees, appeared to increase the possibility of accurately predicting LAI (Table 2), with the 130-degree view producing the best results (estimated $\mathrm{LAI}=3.30$, where actual $\mathrm{LAI}=3.89$ ).

LAl-2000. Data were reprocessed to incorporate the $x, y$ coordinates for individual crowns and to use linearly interpolated above-crown readings. Two processing methods were then used: 1) Lang's (1986) method and 2) Campbell's (1986) ellipsoidal inversion. Both processing methods 
improved iridividual LAl estimates. The t-test results on mean LAI for the two methods were $t=$ 1.988 and 1.565 , respectively, with ellipsoidal inversion appearing the better of the two $(P=0.09$ and 0.16 , respectively).

However, the LAI-2000 produced the least precise individual estimates for each tree of all instruments tested, as shown in Figure 3d. An examination of the times at which LAl-2000 measurements were taken does not help to explain the imprecision. For example, two of the measurements of mulberry 02 were taken $14 \mathrm{~min}$ apart, producing indices of 2.77 and 4.16 (Fig. 3d). Similarly, two measurements of mulberry 01 taken 2 min apart at 1134 and $1136 \mathrm{~h}$ have LAls of 2.86 and 4.25 , while the third measurement taken $2.5 \mathrm{~h}$ later (at $1359 \mathrm{~h}$ ) also produced an $\mathrm{LAl}$ of 2.86. Because of this variability and the fact that bad readings (those for which the instrument lens could not be shaded from direct sunlight) were removed before data processing for analysis, it seems unlikely that LAI underestimation is a function of the lens capturing too much light at particular times of the day.

The image processing method appears to have better precision across the range of times when measurements were taken (Figure 3c). It also initially appears to be less biased than other instruments when data for both tree species are plotted against actual LAI. As actual LAI increases, so does estimated LAl. The LAI-2000 ellipsoidal inversion method also shows less bias in comparison to the AccuPAR (which consistently underestimates LAI at all measurement points) and $\mathrm{Cl}-100$ instruments. The consistent underestimation by the AccuPAR (Figure 3a) may be a function of the distance it was placed from the bottom of the isolated tree crown and the times of day when most measurements were taken. The instrument is designed for the probe to be inserted into tree canopies rather than held beneath a single tree crown. Holding it beneath the crown places it in a position where it is more likely to receive sunbeams directly, before they pass through the crown, leading to underestimates of LAl. Field data records support this, revealing that below-crown measurements taken with this instrument before $1000 \mathrm{~h}$ (PST) and after $1300 \mathrm{~h}$ registered high transmission coefficients from sunlight directly striking the probe without first passing through the tree crown, resulting in consistent underestimation of LAl. Examining the highest LAl estimates (those closest to actual) produced by the instrument provides further support for this hypothesis (Figure 4a). Approximately $86 \%$ (12 of 14) high LAls measured before $1200 \mathrm{~h}$ were taken from north and west cardinal directions, where the probe was partially shaded by the tree crown as the sun rose in the east. During the afternoon as the sun set to the west, $100 \%$ of the high LAl measurements were from beneath the north and east sides of the crown. Placing the instrument in the crown may have resulted in more accurate measurements from all cardinal points.

The $\mathrm{Cl}-100$ instrument bias (Figure $3 b$ ), although
Figure 4. Percentage of measurements taken in each cardinal direction for two instruments, a) AccuPAR, b) $\mathrm{Cl}-100$, that produced more accurate LAl estimates. Fourteen sets of measurements were made in the morning and 10 sets in the afternoon ( $n=14$ in morning and $n=10$ in afternoon). 
not as great as the AccuPAR, shows a trend toward returning a mean LAl of approximately 3.3 (range $=2.37$ to 4.12 ) across the actual LAI range of 2.25 to 6.29 for the eight trees included in the study. Although this instrument takes a hemispherical photograph to estimate LAI, there may be a bias in the software program's conversion of the photograph into the high-contrast image from which pixels are counted to determine LAI. The most accurate LAIs (approximately 73\%) estimated by the instrument during morning hours were captured from south and east cardinal measuring points beneath the crown (Figure 4b). Seventy percent of the most accurate estimates captured in the afternoon were produced from south and west points, suggesting that the instrument may produce better estimates when placed beneath those sides of urban trees nearest the direct beam of the sun, just the opposite of the AccuPAR. It should be stressed again, however, that a larger sample size is needed to determine whether this is true, particularly because the $\mathrm{Cl}$ 100 registered several accurate measurements at other cardinal points.

Although graphs of the data for image processing, LAl-2000 ellipsoidal, and regression equation methods display an increase in estimated LAI as actual $L A$ I increases, they also raise a question. Does the estimated LAl actually increase, or is the apparent increase a function of plotting the data for both species? For example, when the cherry tree data are eliminated and the mulberry tree data are examined separately, none of the methods return mean LAl estimates that increase in proportion to actual indices (Figure 3 ). The inclusion of the cherries, with their high actual LAI, may unduly influence the overall results. A larger sample size for each of the two species is necessary to determine whether this is the case.

Of those methods appearing to have the best potential for estimating the LAI of open-grown trees in urban settings, the image processing, $\mathrm{Cl}$ 100 , and regression equation methods are also easiest to apply in the field. The latter produces the most rapid estimates, but only if shading coefficients are predetermined for the species being measured. The first two methods provide field technicians the ability to view the actual tree crown being measured, enabling the operator to adjust camera positioning for the best view of the crown. Because both are essentially photographic methods, they can be used in a variety of sky conditions and do not require above-crown measurements, as do the AccuPAR and LAI2000. Obtaining those above-crown measurements poses a problem in urban settings where the nearest open space may not provide an environment similar to above-crown light conditions. Similarly, buildings in urban core areas may partially or totally shade tree crowns, eliminating the light necessary for below-crown measurements.

\section{Conclusions}

None of the methods used as described in this study produced satisfactory or unambiguous measurements of LAl of individual trees. Although t-test results indicate a potential for using the image processing method to estimate leaf area index across species of open-grown trees in urban settings, graphs of the data reveal a bias for this and all methods when the two species measured are examined separately. The source of the bias toward returning LAl estimates that do not increase as actual LAl increases must be determined through additional studies incorporating a larger sample size from a variety of species of different ages and crown architecture. Converting theories on light interception by isolated plants into working software might also allow for the reprocessing of primary data in a way that accounts for discontinuity in canopies.

Preliminary indications suggest that instrument placement beneath each tree crown could improve LAl estimations because the best AccuPAR estimates came from locations that were partially shaded in the morning (north and west sides) and afternoon (north and east sides), and $\mathrm{Cl}-100$ best estimates came from locations that were sunlit (south and east sides in the morning, south and west sides in the afternoon).

As a result of analyses, the $\mathrm{Cl}-100$, image processing, LAl-2000, and logarithmic regression equation methods will be tested further. Any method used to estimate leaf area index in urban trees must have the flexibility to be used in 
the wide variety of conditions existing within cities, including the presence of homes, buildings, and signs adjacent to trees, occlusion of direct sunlight by nearby buildings, traffic, and weatherassociated winds. Although the LAl-2000 may have limited application within cities, only the AccuPAR will be eliminated because of consistent $L A I$ underestimation during all times of day that the instrument was used under clear sky conditions.

Acknowledgements. This project would not have been possible without the assistance of representatives from CID, Inc., Decagon Devices, Inc., and LICOR, Inc. We are indebted to all those who provided their assistance, particularly to Linda George, who maintains the Solano Urban Forest Research Site and to field technicians Uma Ramakrishnan, Richard Bagoisan, Melissa Kaufman, Nina Luttinger, and TinWah Wong. We especially thank Sylvia Mori, Dr. James Simpson, and Dr. Patricia Lindsey for providing statistical and technical support that was critical to this study.

\section{Literature Cited}

Baskerville, G.L. 1972. Use of logarithmic regression in the estimation of plant biomass. Can. J. For. 2:49-53.

Bonhomme, R., and P. Chartier. 1972. The interpretation and automatic measurement of hemispherical photographs to obtain sunlit foliage area and gap frequency. Isr. J. Agric. Res. 22:53-61.

Botkin, D.B. 1986. Remote Sensing of the Biosphere. National Academy of Sciences, Report of the Committee on Planetary Biology, National Research Council, Washington, DC.

Burkman, W.G., R. Anderson, K. Stolte, V.J. LaBau, I. Millers, M. Miller-Weeks, and M. Schomaker. 1993. Crown condition classification. In Conkling, B.L. and G.E. Byers (Eds. Forest Health Monitoring Field Methods Guide, Internal report. U.S. Environmental Protection Agency, Las Vegas, NV.

Campbell, G.S. 1986. Extinction coefficients for radiation in plant canopies calculated using an ellipsoidal inclination angle distribution. Agric. For. Meteorol. 36:317-321.

Campbell, G.S., and J.M. Norman. 1988. The description and measurement of plant canopy structure, pp 1-19. In Russell, G., B. Marshall, and P.G. Jarvis (Eds.). Plant Canopies: Their Growth, Form and Function (ed. G. Russell), Society for Experimental Biology, Seminar Series 29, Cambridge University Press, Cambridge, England.
Gardner, T.J., and T.D. Sydnor. 1987. Preliminary studies in photographic determination of tree shade capacity. HortScience 22 (1):145-148.

Gholz, H.L., S.A. Vogel, W.P. Cropper, K. McKelvey, K.C. Ewel, R.O. Teskey, and P.J. Curran, 1991. Dynamics of canopy structure and light interception in Pinus elliottii stands, North Florida. Ecol. Monogr. 6:33-51.

Lang, A.R.G. 1987. Simplified estimate of leaf area index from transmittance of the sun's beam. Agric. For. Meteorol. 41:179-186.

Lang, A.R.G., and R.E. McMurtrie. 1992. Total leaf areas of single trees of Eucalyptus grandis estimated from transmittances of the sun's beam. Agric. For. Meteorol.58: 79-92.

Lang, A.R.G., and X. Yueqin. 1986. Estimation of leaf area index from transmission of direct sunlight in discontinuous canopies. Agric. For. Meteorol. 37:229-243.

Lindsey, P.A., and N.L. Bassuk. 1992. A nondestructive image analysis technique for estimating whole-tree leaf area. HortTechnology. 2(1):66-72.

Marshall, J.D., and R.H. Waring. 1986. Comparison of methods of estimating leaf-area index in oldgrowth Douglas-fir. Ecology. 67:975-979.

Martens, S.N., S.L. Ustin, and R.A. Rosseau. 1993. Estimation of tree canopy leaf area index by gap fraction analysis. For. Ecol. Manage. 61:91-108.

McPherson, E.G. 1992. Accounting for benefits and costs of urban greenspace. Landscape Urban Plann. 22:41-51.

McPherson, E.G., E. Dougherty, and J.R. Simpson. Unpublished data. Crown density estimates for six tree species. USDA For. Serv., Pac. Southw. Res. Sta.

Mori, S. 1996. Letter to P. Peper on statistical methods for study analysis.

Nel, E.M., and C.A. Wessman. 1993. Canopy transmittance models for estimating forest leaf area index. Can. J. For. Res. 23:2579-2586.

Neumann, H.H., G. DenHartog, and R.H. Shaw. 1989. Leaf area measurements based on hemispheric photographs and leaf-litter collection in a deciduous forest during autumn leaf-fall. Agric. For. Meteorol. 45:325-345.

Norman, J.M., and G.S. Campbell. 1989. Canopy structure, pp 301-325. In Pearcy, R.W., J. Ehleringer, H.A. Mooney, and P.W. Rundel (Eds.). Plant Physiological Ecology: Field Methods and Instrumentation. Chapman and Hall, New York, NY.

Norman, J.M., and J.M. Welles. 1983. Radiative transfer in an array of canopies. Agron. J. 75: 481-488. 
Nowak, D.J. 1994. Urban forest structure: The state of Chicago's urban forest, pp 3-18. In McPherson, E.G., D.J. Nowak, and R.A. Rowntree (Eds.). Chicago's Urban Forest Ecosystem: Results of the Chicago Urban Forest Climate Project. USDA For. Serv. Gen. Tech. Rep. NE-186. Radnor, PA.

Nowak, D.J. 1996. Estimating leaf area and leaf biomass of open-grown deciduous urban trees. For. Sci. 42(4):504-507.

Pierce, L.L., and S.W. Running. 1988. Rapid estimation of coniferous forest leaf area index using a portable integrating radiometer. Ecology. 69:1762-1767.

Welles, J.M., and J.M. Norman. 1991. Instrument for indirect measurement of canopy architecture. Agron. J. 83:818-825.

Whittaker, R.H., and G.M. Woodwell. 1968. Dimension and production relations of trees and shrubs in the Brookhaven forest, New York. J. Ecol. 56:1-25.

Wilkinson, D.M. 1991. Can photographic methods be used for measuring the light attenuation characteristics of trees in leaf? Landscape Urban Plann. 20:347-350.

Wagar, J.A., and G.M. Heisler. 1986. Reduction of solar radiation by tree crowns. Progress in Solar Energy. American Section of the International Solar Energy Society, Inc.

Winer, A.M., L. Chinken, J. Arey, and R. Atkinson. 1995. Critical Evaluation of a Biogenic Emission System for Photochemical Grid Modeling in California. Final report to the California Air Resources Board, Contract No. 93-725, Sacramento, CA.

Yan, Y. 1996. Letter to the author from CID, Inc. application engineer. 6 May.
Western Center for Urban Forest Research and Education

Pacific Southwest Research Station

USDA Forest Service

c/o Department of Environmental Horticulture

University of California

Davis, CA 95616-8587

Résumé. La précision de cinq méthodes d'estimation de la surface foliaire a été comparée avec huit gros arbres à feuilles caduques, six étant des mûriers blancs (Morus alba) et deux des cerisiers tardifs (Prunus serotina var. rufula). Les méthodes ont fait usage de quatre instruments (AccuPAR Ceptometer, $\mathrm{Cl}-100$ Plant Canopy Analyzer, Image Processing avec le AgVision System, LI-COR LAI-2000 Plant Canopy Analyzer) et ont requis l'application d'équations logarithmiques de régression. La méthode Image Processing s'est avérée la plus fiable en probabilité pour estimer avec précision la surface foliaire $(P=0,99)$. Cependant, toutes les méthodes ont démontré des biais en ce sens que l'estimation de la surface foliaire de s'accroissait pas au même rythme que les données réelles lorsque les données relatives aux mûriers étaient étudiées séparément de celles des cerisiers.

Zusammenfasung. Wir verglichen die Genauigket von fünf Methoden, die zur Schätzung des Blattflächenindexes (LAI) angewendet werden, an acht freistehenden Laubbäumen einschließlich 6 Maulbeeren (Morus alba) und 2 Chisos-Kirschen (Prunus serotina var, rufula). Die Methoden umfasst den Einsatz von vier Instrumenten (AccuPAR Ceptometer, $\mathrm{Cl}-100$ Plant Canopy Analyzer, image processing mit dem AgVision System, LI-COR LAl-2000 Plant Canopy Analyzer) und die Anwendung einer logarythmischen Rückführungsgleichung. Die "image processing" Methode zeigte die höchste Zuverlässigkeit bei der Bestimmung des $\operatorname{LAl}(P=0,99)$. In der Gesamtbetrachtung aller Methoden konnte kein Anstieg des LAI beobachtet werden, während bei einer separaten Untersucchung der Maulbeeren und Kirschen der LAI tatsächlich anstieg. 